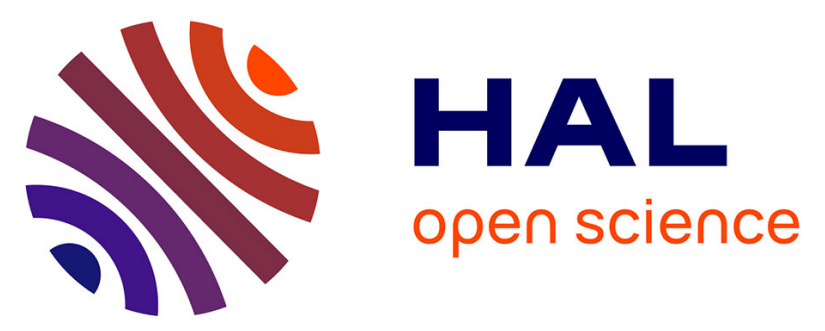

\title{
Glucose-based spiro-oxathiazoles as in vivo anti-hyperglycemic agents through glycogen phosphorylase inhibition
}

\author{
David Goyard, Bálint Kónya, Katalin Czifrák, Paolo Larini, Fanny \\ Demontrond, Jérémy Leroy, Sophie Balzarin, Michel Tournier, Didier Tousch, \\ Pierre Petit, et al.
}

\section{To cite this version:}

David Goyard, Bálint Kónya, Katalin Czifrák, Paolo Larini, Fanny Demontrond, et al.. Glucose-based spiro-oxathiazoles as in vivo anti-hyperglycemic agents through glycogen phosphorylase inhibition. Organic \& Biomolecular Chemistry, 2020, 18 (5), pp.931-940. 10.1039/C9OB01190K . hal-02942989

\section{HAL Id: hal-02942989 \\ https://hal.univ-grenoble-alpes.fr/hal-02942989}

Submitted on 10 Nov 2020

HAL is a multi-disciplinary open access archive for the deposit and dissemination of scientific research documents, whether they are published or not. The documents may come from teaching and research institutions in France or abroad, or from public or private research centers.
L'archive ouverte pluridisciplinaire HAL, est destinée au dépôt et à la diffusion de documents scientifiques de niveau recherche, publiés ou non, émanant des établissements d'enseignement et de recherche français ou étrangers, des laboratoires publics ou privés. 


\title{
ARTICLE
}

\section{Glucose-based spiro-oxathiazoles as in vivo anti-hyperglycemic agents through glycogen phosphorylase inhibition}

Received 00th January 20xx, Accepted 00th January 20xx DOI: $10.1039 / x 0 \times x 00000 x$

David Goyard, ${ }^{a}$ Bálint Kónya, ${ }^{b}$ Katalin Czifrák, ${ }^{b}$ Paolo Larini, ${ }^{a}$ Fanny Demontrond, ${ }^{a}$ Jérémy Leroy, Sophie Balzarin, ${ }^{c}$ Michel Tournier, ${ }^{c}$ Didier Tousch, ${ }^{c}$ Pierre Petit, ${ }^{c}$ Cédric Duret, ${ }^{d, e}$ Patrick Maurel, ${ }^{d, e}$ Tibor Docsa, ${ }^{f}$ Pál Gergely, ${ }^{f}$ László Somsák, ${ }^{b}$ Jean-Pierre Praly, ${ }^{a} *$ Jacqueline Azay-Milhau, ${ }^{c}$ and Sébastien Vidal ${ }^{\mathrm{a}} *$

\begin{abstract}
The design of glycogen phosphorylase (GP) inhibitors targeting the catalytic site of the enzyme is a promising strategy for a better control of hyperglycaemia in the context of type 2 diabetes. Glucopyranosylidene-spiro-heterocycles have been demonstrated as potent GP inhibitors, and more specifically spiro-oxathiazoles. A new synthetic route has now been elaborated through 1,3-dipolar cycloaddition of an aryl nitrile oxide to a glucono-thionolactone affording in one step the spiro-oxathiazole moiety. The thionolactone was obtained from the thermal rearrangement of a thiosulfinate precursor according to Fairbanks' protocols, although with a revisited outcome and also rationalised with DFT calculations. The 2naphthyl substituted glucose-based spiro-oxathiazole $5 \mathrm{~h}$, identified as one of the most potent GP inhibitors $\left(\mathrm{K}_{\mathrm{i}}=160 \mathrm{nM}\right.$ against $\mathrm{RMGPb}$ ) could be produced on the gram-scale from this strategy. Further evaluation in vitro using rat and human hepatocytes demonstrated that compound $\mathbf{5} \boldsymbol{h}$ is a druggable anti-hyperglycaemic compound performing slightly better than DAB used as a positive control. Investigation in Zucker $f a / f a$ rat model in acute and subchronic assays further confirmed the potency of compound $\mathbf{5 h}$ since it lowered blood glucose levels by $\sim 36 \%$ at $30 \mathrm{mg} / \mathrm{kg}$ and $\sim 43 \%$ at $60 \mathrm{mg} / \mathrm{kg}$. The present study is one of the few in vivo investigations for glucose-based GP inhibitors and provides data in animal models for such drug candidates.
\end{abstract}

\section{Introduction}

Diabetes mellitus is one of the most severe global health problems of the $21^{\text {st }}$ century. According to the International Diabetes Federation (IDF) 425 million people, 9\% of the adult population suffer from this disease, many of them may even remain undiagnosed. The number of diabetic patients is predicted to reach close to 700 million by 2045 with the most significant increase in low and medium income territories of Asia, Africa and South-America. In 2017 USD 727 billion was spent for diabetes treatments representing more than $12 \%$ of the global health expenditures. Most of the diabetic patients (>90\%) belong to the so-called type 2 diabetes mellitus (T2DM)

a. Institut de Chimie et Biochimie Moléculaires et Supramoléculaires, UMR 5246, CNRS, Université Claude Bernard Lyon 1, Bâtiment Lederer, 1 Rue Victor Grignard, F-69622 Villeurbanne, France. Fax: +33472448 109; Tel: +33 472448 349; E-mail: sebastien.vidal@univ-lyon1.fr

${ }^{b .}$ Department of Organic Chemistry, University of Debrecen, POB 400, $\mathrm{H}-4002$ Debrecen, Hungary

Montpellier University, EA7288, Biocommunication in cardiometabolism (BC2M), Montpellier, France

d. INSERM U1040, Montpellier, France

e. Montpellier University, UMR-1040, Montpellier, France

f. Institute of Medical Chemistry, University of Debrecen, $P O B$ 7, Nagyerdei krt. 98, H-4012 Debrecen, Hungary

Electronic Supplementary Information (ESI) available: [details of any supplementary information available should be included here]. See DOI: $10.1039 / x 0 x \times 00000 x$ when the organism does not produce insulin in sufficient quantities and/or the peripheral cells are more or less resistant to the insulin action to promote uptake of blood glucose. Due to the constantly high levels of glycaemia, short and especially long term complications are developed being frequent causes of death, thereby diabetes is one of the main contributors to global mortality. At present no causal therapy is known, treatment regimens aim at maintaining blood sugar levels around the normoglycemic value of $\sim 6.1 \mathrm{mM}$ by applying various medications. ${ }^{1,2}$

Hepatic glucose output is elevated in T2DM patients. This glucose production consists of glycogenolytic and gluconeogenetic components and the latter is known to be cycled through the glycogen pool. ${ }^{3,4}$ Therefore, liver glycogen phosphorylase, the rate limiting enzyme of glycogen degradation has become a validated target to find potential new therapeutical possibilities against T2DM. ${ }^{4,5}$

A broad variety of synthetic compounds and natural products have been tested as inhibitors of glycogen phosphorylase $(G P)^{6-12}$ mainly with the most easily available rabbit muscle $\mathrm{GPb}$ (RMGPb). ${ }^{13}$ Many of these compounds' complexes with the GP enzyme were also studied by X-ray crystallography. From the so discovered seven GP binding sites the most investigated one is the catalytic (or active) site which can accommodate D-glucose (the physiological inhibitor of the enzyme) and a large array of glucose derivatives. ${ }^{14,15}$ The most 
efficient glucose derived inhibitors belong to three main compound categories: glucopyranosylidene-spiroheterocycles, ${ }^{14-17} N$-acyl- $N$ '- $\beta$-D-glucopyranosyl ureas, ${ }^{14,} 15$ and $C$ - $\beta$-D-glucopyranosyl heterocycles. ${ }^{18-26}$ in each category several inhibitors have submicromolar and even low nanomolar inhibitor constants. Some of these glucose analog GP inhibitors (GPIs) were subjected to various physiological investigations to show significant blood sugar diminishing effects in streptozotocin-induced diabetic rats, ${ }^{27}$ restoration of whole body insulin sensitivity, ${ }^{28}$ triggering of mitochondrial oxidation and mTORC2 (mammalian target of rapamycin complex 2) signaling, ${ }^{29}$ and improvement of pancreatic $\beta$-cell function. $^{30}$

Among the anomeric spirocycles the most efficient inhibitors are the glucopyranosylidene-spiro-isoxazolines ${ }^{31,32}\left(\mathrm{~K}_{\mathrm{i}}=0.63\right.$ $\mu \mathrm{M}$ against RMGPb for a 2-naphthyl derivative) and the glucopyranosylidene-spiro-oxathiazoles ${ }^{33}\left(K_{i}=0.16 \mu \mathrm{M}\right.$ against $\mathrm{RMGPb}$ for a 2-naphthyl derivative) while their xylopyranosylidene counterparts remained inactive. ${ }^{34}$ The glucose derived isoxazolines were shown to have significant inhibitory effects in rat and human hepatocytes, and also diminished hepatic glucose production in Zucker $\mathrm{fa} / \mathrm{fa}$ rats by single dose oral administration. ${ }^{35}$ In this paper a new synthesis of the glucopyranosylidene-spiro-oxathiazoles, their in vitro enzymatic evaluation, as well as cellular and in vivo evaluations of the best inhibitor as an antihyperglycaemic agent are described.

\section{Synthesis}

Our previously explored strategy ${ }^{36}$ was developed for the synthesis of glycosylidene-spiro-oxathiazoles. The key step was the oxidative spirocyclization of $O$-peracetylated glycosyl hydroximothioates $^{37}$ (e.g. 2) to glycosylidene-spirooxathiazoles 3 and 4 (Scheme 1), a transformation achieved readily upon treatment with NBS in refluxing halogenated solvents $\left(\mathrm{CCl}_{4}, \mathrm{CHCl}_{3}\right)$. When the hydroximothioate moiety displayed an aryl substituent, our earlier study showed that the cyclization proceeded well whatever the configuration of the pyranose ring (D-gluco, D-galacto) or that of the anomeric centre $(\alpha / \beta)$. Moreover, the cyclization was stereoselective, yielding preferentially $1 S$-spiro-oxathiazoles in the D-gluco, Dgalacto series. Later on, this methodology was applied for preparing D-gluco ${ }^{33,38}$ or D-xylo ${ }^{34}$ analogues. In this last series, the cyclization was shown to occur with the opposite stereoselectivity, thus favouring formation of the $1 R$ configured spiro-oxathiazoles. The compounds studied in more details displayed the aromatic pharmacophores a-i (Scheme 1). ${ }^{33,38}$ For the first step of the sequence, earlier studies ${ }^{37}$ showed that, under basic conditions, 2,3,4,6-tetra-O-acetyl-1thio- $\beta$-D-glucopyranose 1 reacted readily with hydroximoyl chlorides to afford the corresponding glucosyl hydroximothioates $\mathbf{2}$. For improving access to glucosinolates, ${ }^{39}$ a procedure involving the in situ formation of an oximoyl chloride from the oxime using inexpensive bleach, which is then reacted directly under basic conditions with thioglycopyranose has been reported. However, comparison of these procedures showed that the conventional method to hydroximothioates resulted in higher yields. ${ }^{34}$ Therefore, the two-step conventional method has been used to prepare new analogs in the present work $\left(\mathrm{Ar}=p-\mathrm{CO}_{2} \mathrm{H}-\mathrm{C}_{6} \mathrm{H}_{4}, 2\right.$-quinolinyl, 9phenanthryl) with either hydrogen bond donors or acceptors or expanded aromatic moieties for better interactions of the aglycons in the $\beta$-pocket of the enzyme's catalytic site.

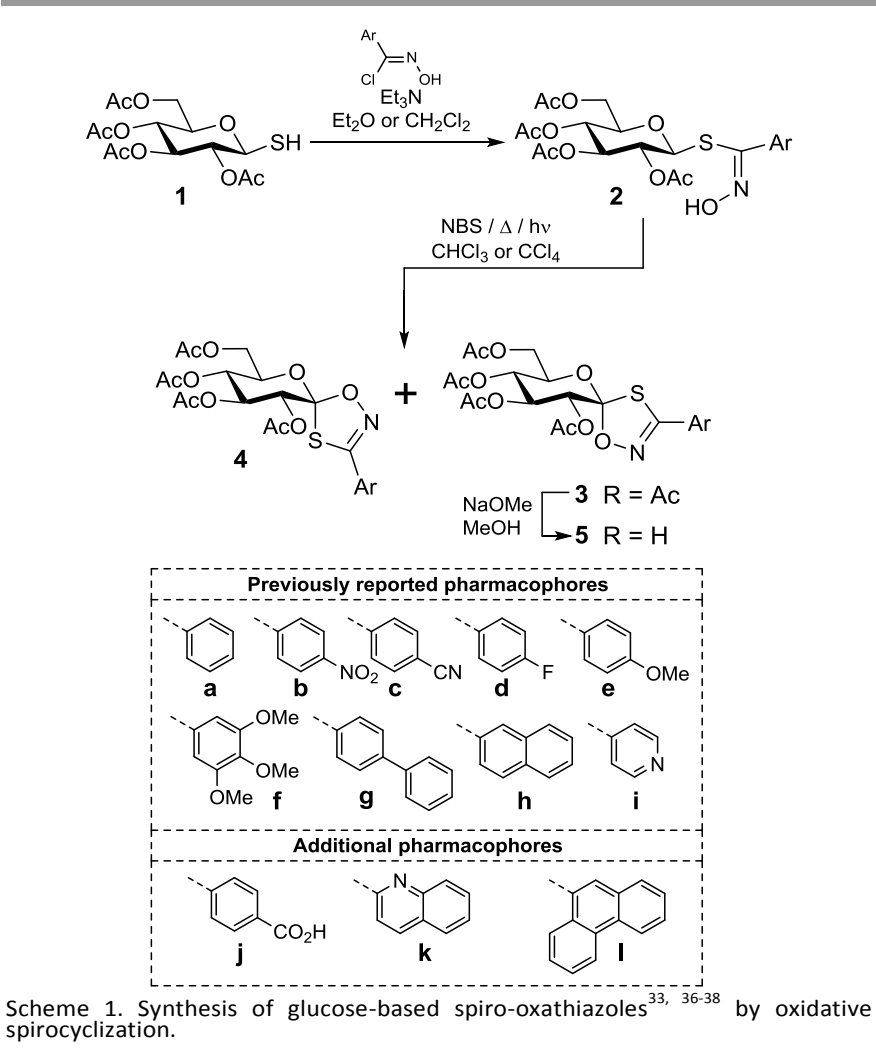

Glucosyl hydroximothioates precursors $\mathbf{2} \mathbf{j}$-I were obtained in variable yields (Table 1 ), their spirocyclization proceeded as generally observed, yielding preferentially the $1 S$-configured spirobicycles $\mathbf{3 j - I}$. The anomeric configurations for compounds 3j-I were deduced from NMR spectroscopy which revealed significantly different chemical shifts for the $\mathrm{H} 3$ and $\mathrm{H} 5$ pyranosylidene protons, and the C1 spiro carbon..$^{33,34,36,38}$ As noted earlier for $1 S$-configured analogs, these signals were respectively close to $5.65,4.45$, and $122.5 \mathrm{ppm}$. The protected $1 S$-spirobicylces were deacetylated in high yield under Zemplén conditions.

Enzyme kinetic studies ( $\mathrm{IC}_{50}$ and/or $K_{\mathrm{i}}$ measurements) were then performed to evaluate whether the prepared spirobicycles were GP inhibitors. Then, the most potent candidates were further evaluated through in vitro and in vivo biological assays to demonstrate their pharmacological interest. Therefore, substantial quantities of material were needed, typically gram- to multi-gram-scale. This called for the design and development of an unprecedented route to Dglucose based spiro-oxathiazoles, with the hope that a stereoselectivity higher than that of the NBS-mediated cyclization could be achieved. 
Table 1: Stereoselective cyclization of $\beta$-D-glucosyl thiohydroximates $\mathbf{2}$ to glucose-based spiro-oxathiazoles $\mathbf{3 - 4}$ and their deacetylation to . $^{33,36,38}$

\begin{tabular}{|c|c|c|c|c|}
\hline & \multicolumn{4}{|c|}{ isolated yields (\%) } \\
\hline $\mathrm{Ar}$ & 2 & 3 & 4 & 5 \\
\hline $\mathbf{a}$ & $90^{37}$ & $46^{36}$ & 11 & $90^{36}$ \\
\hline b & $60^{37}$ & $33^{\mathrm{a}}$ & $16^{\mathrm{a}}$ & 71 \\
\hline c & 48 & $15^{\mathrm{a}}$ & $7^{\mathrm{a}}$ & 84 \\
\hline d & $65^{37}$ & $30^{36}$ & $16^{36}$ & 79 \\
\hline e & $71^{37}$ & $69^{\mathrm{a}}$ & $17^{\mathrm{a}}$ & 79 \\
\hline$f$ & 85 & \multicolumn{2}{|c|}{ unselective reaction } & - \\
\hline $\mathbf{g}$ & 40 & $61^{a}$ & $18^{\mathrm{a}}$ & 97 \\
\hline $\mathrm{h}$ & 78 & $36^{\mathrm{a}}$ & $16^{\mathrm{a}}$ & 94 \\
\hline i & 78 & 0 & 30 & - \\
\hline $\mathbf{j}$ & 53 & 50 & - & 73 \\
\hline k & 35 & 36 & - & 88 \\
\hline $\mathrm{I}$ & 86 & 49 & - & $>95 \%$ \\
\hline
\end{tabular}

a Yields were calculated based on the isolated yields and on the amount of product present in the $1 R S$-mixtures (ratio measured by ${ }^{1} \mathrm{H} \mathrm{NMR}$ ) unresolved by column chromatography.

\section{A new route to spiro-oxathiazoles by 1,3-dipolar cycloaddition of nitrile oxides to gluconothionolactone}

The design of a new access to spiro-oxathiazoles was inspired by our reported synthesis of glycosylidene-spiro-isoxazolines based on 1,3-dipolar cycloaddition of nitrile oxides to exomethylene glycals (pyranoid exo-glucals). ${ }^{31,32,35}$ Concerted reactions are advantageous as regard to atom economy, experimental conditions and yield, so they are of particular interest in carbohydrate chemistry. We and others could demonstrate that such cycloadditions occurred with a high stereocontrol, the dipole attacking the exo-methylene carbohydrate from the $\alpha$-face of the D-glucopyranosylidene ring, ${ }^{40}$ while for steric and electronic reasons, regioselectivity was equally high, favouring attack of the anomeric carbon by the oxygen atom of nitrile oxides in all cases studied. The more complex cycloaddition of nitrones ( $E$ and/or $Z$ configurations, endo and/or exo transition states) to pyranoid exo-glycals led to mixtures of cis/trans and $\alpha / \beta$ products, but the $\alpha$-face approach usually predominated, or was even exclusive in some cases. $^{41,42}$
Based on this 1,3-dipolar cycloaddition analogy, the known Dglucono- $\delta$-thionolactone $12^{43-45}$ appeared as the required precursor towards spiro-oxathiazoles. Moreover, benzylated Dglucono- $\delta$-thionolactone $\mathbf{1 2}$ appeared to be a readily accessible substrate, based on the one-pot two-step synthetic route by the group of Fairbanks. ${ }^{46,} 47$ 1-Thiosugars reacting with tert-butyl-sulfinyl chloride in the presence of triethylamine were converted into glycosyl S-tert-butyl thiosulfinates (within $10 \mathrm{~min}$ at room temperature), which upon thermolysis (10-20 $\mathrm{min}$ in refluxing toluene) yielded various glycono-thionolactones, and in particular D-glucono- $\delta$ thionolactone $\mathbf{1 2}$ in a notable $85 \%$ yield. ${ }^{47}$ Glycono- $\delta$ thionolactones have been shown to react with dienes, diazoalkanes, and carbenoids, ${ }^{48}$ and the thermolysis of the obtained dihydro-1,2,3-, and -1,3,4-thiadiazoles has been investigated. $^{49}$

We developed this new route for synthesizing compound $\mathbf{5 h}$ on the multi-gram scale considering its remarkable inhibitory properties. The direct synthesis of dithiocarbonate $\mathbf{8}$ from the commercially available hemiacetal $\mathbf{6}$ using tosyl chloride and potassium $O$-ethyl dithiocarbonate under phase-transfer conditions ${ }^{50}$ gave in our hands poor results. However, the twostep protocol in one-pot reported by Vasella ${ }^{51}$ (treatment of hemiacetal 6 with $\mathrm{CCl}_{4}$ and $\mathrm{HMPT}$, then with potassium $O$-ethyl dithiocarbonate at $-40^{\circ} \mathrm{C}$, for which basic conditions dictate the choice of base-stable protective groups) afforded the desired dithiocarbonate 8 via the intermediate chloride 7 (Scheme 2). Subsequent methanolysis delivered the 2,3,4,6-tetra-O-benzyl1-thio-D-glucopyranose 9 in a $85 \%$ overall yield. Thiol 9 was reacted with tert-butyl-sulfinyl chloride ${ }^{47}$ to afford the $\beta$ configured thiosulfinate 10 in $90 \%$ yield as a $\sim 1: 1 \mathrm{~S}(S), S(R)$ diastereoisomeric mixture. While mass spectrometry displayed a main peak as expected $\left(m / z=661[\mathrm{M}+\mathrm{H}]^{+}\right)$, the formed diastereoisomers $\mathbf{1 0}$ were visible as two close spots on TLC plates. They were purified by column chromatography but could not be fully separated in pure form. The ${ }^{1} \mathrm{H}$ NMR spectra of this mixture displayed two singlets for the diastereotopic tert-butyl groups resonating at 1.40 and $1.58 \mathrm{ppm}$, respectively.

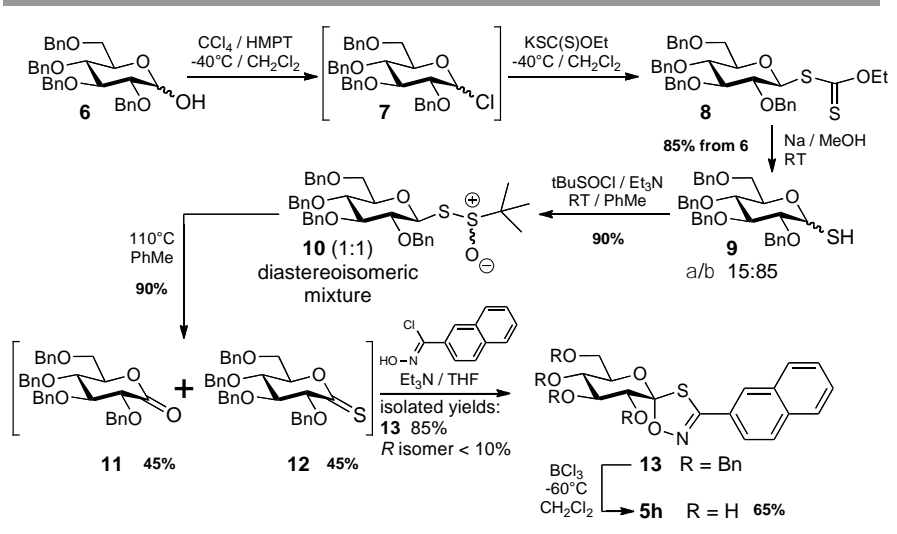

Scheme 2. New access to $1 S$-glucopyranosylidene-spiro-oxathiazole by nitrile oxidethionolactone 1,3-dipolar cycloaddition 
Following Fairbanks' procedure, thermal elimination was carried out in refluxing toluene with either the crude thiosulfinate 10 (two-step one-pot process) or the purified diastereoisomeric mixture, but disappointingly, the yields recorded for the thionolactone $\mathbf{1 2}$ were around 45\%, significantly lower than the $85 \%$ yield reported. ${ }^{47}$ As a byproduct, the glucono- $\delta$-lactone $\mathbf{1 1}$ was identified and actually isolated in an equal amount when the reaction time was increased thus allowing for the complete conversion of both thiosulfinate diastereoisomers $\mathbf{1 0}$. Formation of an undesired analogous $\delta$-lactone was observed by Fairbanks ( $20 \%$ yield) during the thermal elimination at $120^{\circ} \mathrm{C}$ of a rhamno-configured thiosulfinate. ${ }^{46}$ Presence of di-tertbutylthiosulfinate as a byproduct (vide infra, text and Fig. 3, Fig. 4) has been noted as another limitation of the method. ${ }^{47}$ These disappointing and intriguing observations led to repeated trials for enhancing the yield of thiolactone 12, but without success. TLC monitoring of the reaction revealed that the more mobile thiosulfinate diastereoisomer $\mathbf{1 0}$ was converted faster than the other one, and while its spot decreased visually on TLC plates, that of the thionolactone $\mathbf{1 2}$ increased. Seemingly, after complete conversion of the more reactive thiosulfinate, there was no increase in the amount of D-glucono- $\delta$-thionolactone $\mathbf{1 2}$ from the qualitative analysis of TLC, and disappointingly, the isolated yields never exceeded $45 \%$. Analysis of MS data collected for the fractions recovered from column chromatography confirmed the formation of Dgluconolactone $11\left(\mathrm{~m} / z[\mathrm{M}+\mathrm{Na}]^{+}=561\right)$, and showed the presence of an unidentified product $\left(\mathrm{m} / \mathrm{z}=607 \mathrm{M}+\mathrm{H}^{+}\right.$) (vide infra, text and Fig. 1). After inquiring about these discrepancies, Prof. A.J. Fairbanks kindly provided us with the investigator's original report. It appeared that the $85 \%$ yield reported ${ }^{47}$ for the thionolactone $\mathbf{1 2}$ was overestimated as, from the report, it corresponded to a crude product " contaminated with tert-butyl species, possibly di-tert-butyl thiosulfinate. Yields projected to approximately 54-56\%". Presence of byproducts, allegedly mixed disulfides or disproportionation products, was also supposed, but not proven. A note clearly stated that the yield estimated by ${ }^{1} \mathrm{H}$ NMR for the thionolactone 12 were 54 and $56 \%$ (close to the $43-53 \%$ yields observed in the D-galacto series), ${ }^{47}$ so that these data corroborated ours, suggesting the occurrence of at least one unwanted reaction detrimental to the yield of the desired glycono-thionolactone.

D-Glycono-thionolactones are subject to epimerization ${ }^{47}$ at C-2 or 2,3-elimination ${ }^{43}$ under basic conditions. Therefore, Dglucono-? ?-thionolactone $\mathbf{1 2}$ was often used without further purification for the 1,3-dipolar cycloaddition. With the crude thionolactone 12, this step proceeded smoothly in the presence of 2-naphthyl hydroximoyl chloride to afford the spiro-oxathiazole 13 in high yield ( 95\%) and stereoselectivity (9:1 $S / R$ mixture). The diastereoisomeric mixture could be resolved by silica gel column chromatography to afford the desired spiro-oxathiazole $\mathbf{1 3}$ with a $S$-configuration at the spiro-anomeric center ( $85 \%$ isolated yield) and the minor $R$ epimer ( $<10 \%$ yield).
Not surprisingly, the final debenzylation step proved to be problematic, and standard hydrogenolysis in the presence of palladium did not proceed at all, while $\mathrm{Et}_{3} \mathrm{SiH} / \mathrm{I}_{2}{ }^{52}$ resulted in partial deprotection only. Treatments with bromine or NBS and water under various free radical conditions (NBS, $\mathrm{CCl}_{4}, \mathrm{hv}$, with or without $\mathrm{CaCO}_{3} ; \mathrm{NaBrO}_{3} / \mathrm{Na}_{2} \mathrm{~S}_{2} \mathrm{O}_{4}$ ) resulted in complex mixtures, due to partial debenzylations, ${ }^{53,54}$ and/or formation of oxidized products as evidenced by mass spectrometry: in addition to the expected fragments corresponding to the partial or total debenzylation, fragments corresponding to $M+14$ indicated the oxidation of benzyls to benzoates, while others $(M+16$ and $M+32)$ suggested oxidation to sulfoxides and sulfones. Fortunately, debenzylation could be achieved by treatment with $\mathrm{BCl}_{3}$ at $-60^{\circ} \mathrm{C}^{55}$ with careful TLC monitoring to quench the reaction immediately after disappearance of the starting material to avoid further unwanted reactions. Purification by column chromatography delivered the desired final $O$-unprotected spiro-oxathiazole $5 \mathrm{~h}$ ( $815 \mathrm{mg}, 65 \%$ yield). In conclusion, the designed 1,3-dipolar cycloaddition approach between 2-naphthyl nitrile oxide and perbenzylated D-gluconothionolactone 12 was most efficient for synthesizing the corresponding D-glucose-based 1S-3-(2-naphthyl)-spiro-1,4,2oxathiazole 13. Both regio-, and stereo-selectivities were excellent. In contrast to literature reports, the limiting step of this approach was the synthesis of tetra-O-benzyl D-glucono- $\delta$ thionolactone 12 by thermolysis of glucopyranosyl tert-butyl sulfinate precursors $\mathbf{1 0}$. The discrepancies between our results and those of Fairbanks as reported and detailed in an internal document prompted the investigation of the thermolysis mechanism by DFT calculations to better understand the possible path to the desired thionolactone.

\section{Proposed mechanisms for the thermal elimination of thiosulfinates 10 to thionolactone 12}

Various possible modes of reaction were envisaged (Scheme 3 ) since tert-butyl thiosulfinates may undergo thermal elimination by hydrogen atom abstraction through fivemembered cyclic transition states (TS). Glycono-thionolactones being reportedly obtained sometimes in excellent yields, ${ }^{46,} 47$ elimination involving the anomeric proton (path a) was privileged (anomeric effect), thus delivering the desired thionolactone 12 and tert-butyl sulfenic acid. However, elimination might also involve one of the nine equivalent hydrogen atoms of the tert-butyl moiety (path b), which would afford isobutene and the 3-D-glucopyranosyl-thiosulfoxylic acid $14^{56}$ (other name: 3-D-glycopyranosyl-1-oxa-trisulfane). Considering early ${ }^{56}$ and recent ${ }^{57,58}$ reports on the thermolysis of di-tert-butylthiosulfinate (also termed di-tert-butyldisulfane$\mathrm{S}$-oxide, $t \mathrm{BuS}(\mathrm{O}) \mathrm{StBu}),{ }^{57}$ these speculations were reasonable, but the total weight of lactones $\mathbf{1 1}$ and $\mathbf{1 2}$ (ca 90\%, 1:1 ratio) measured after full conversion of both thiosufinates indicated that path $b$ was only a marginal process. 


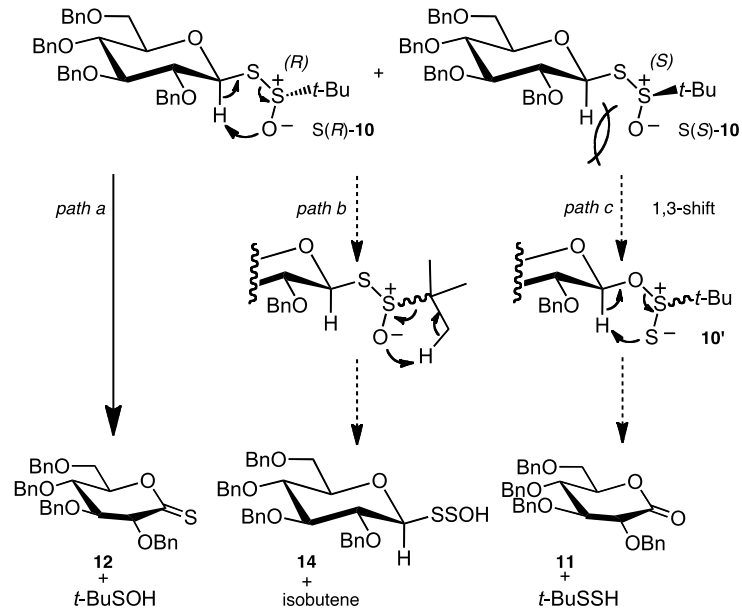

Scheme 3: Possible reaction paths for the thermolysis of D-glucosyl tert-butyl thiosulfinates 10

The puzzling formation of D-gluconolactone $\mathbf{1 1}$ might be due to hydrolysis by water present in trace amount ${ }^{59}$ or to adventitious reactions, as discussed recently, ${ }^{60}$ but since $\mathbf{1 1}$ was detected on TLC plates even at the initial stage of the reaction, and as use of a purified mixture of diastereomeric thiosulfinates $\mathbf{1 0}$ led to similar lactone distribution, this hypothesis was uncertain. As the glucopyranosyl tert-butyl thiosulfinates $\mathbf{1 0}$ must achieve a favourable 5-membered cyclic TS for the thermal elimination to proceed, and because of probable steric clashes between the tert-butyl group and the 2-O-benzyl group for the $S(S)$-diastereoisomer, most probably the $S(R)$ - and $S(S)$-tert-butyl thiosulfinates underwent elimination at different rates, the $(R)$-diastereoisomer reacting faster to deliver thionolactone $\mathbf{1 2}$ through path $a$. Still, another hypothesis was needed to explain the presence of glyconolactone $\mathbf{1 1}$. The thermal rearrangement of $\alpha$ configured glycopyranosyl xanthates to $\alpha$-glycosyl dithiocarbonates has been reported to proceed without inversion of configuration at moderate temperatures (50$\left.65^{\circ} \mathrm{C}\right) .{ }^{61}$ This reported example of the Freudenberg-Schönberg rearrangement ${ }^{62,} 63$ was supposed to occur by an intramolecular 1,3-shift through a 4-membered cyclic TS. ${ }^{61}$ An analogous thermal rearrangement could occur with the less reactive $S(S)$ thiosulfinate (path $c$ ), and the rearranged product with a $O$-glycosidic bond [OS(S) moiety] would be susceptible to afford by thermal elimination the lactone $\mathbf{1 1}$ and tert-butylthiosulfenic acid (tBuSSH). Interestingly, the relative enthalpies for thiosulfinic acid isomers [ $\mathrm{HS}(\mathrm{O}) \mathrm{SH}$, and $\mathrm{HS}(\mathrm{S}) \mathrm{OH}$ ] estimated by theoretical studies at $298 \mathrm{~K}$ in the gas phase were found to be almost the same, ${ }^{64,65}$ suggesting that isomers $\mathbf{1 0}$ and $\mathbf{1 0}^{\prime}$ might have similar energies. While the rearrangement of xanthates to dithiocarbonates is stability driven, the proposed pathway to gluconolactone $\mathbf{1 1}$ might benefit from the activation of the anomeric center (rearrangement favoured) and, in lactone 11, the stabilization of $\mathrm{C}=\mathrm{O}$ bond $(162 \mathrm{kcal} . \mathrm{mol}$ ${ }^{1}$ ) by ca. $50 \mathrm{kcal} . \mathrm{mol}^{-1}$ compared to the $\mathrm{C}=\mathrm{S}$ thiocarbonyl bond $\left(115 \mathrm{kcal} . \mathrm{mol}^{-1}\right)$ in thionolactone $\mathbf{1 2} .^{66}$ Eventually, calculations were carried out to identify the reaction pathway leading to the gluconolactone byproduct (hydrolysis versus thermal rearrangement followed by elimination).

\section{DFT Calculations}

As a representative model, the tetra-O-methyl analog of $\mathbf{1 0}$ was chosen (See supporting information for further details) to have reasonable computational time. The numbering of molecules applied is the same for both $O$-benzyl- (synthetic work) and $O$-methyl-protected (computational approach) analogues, but using italicized types in the last case.

Our calculations addressed first the three reaction pathways mentioned above (Scheme 3), namely the two possible direct internal eliminations (Ei) (path a, path $b$ ), then path $c$, in which an internal O,S-rearrangement by 1,3-shift was supposed to occur prior to the Ei elimination. The stereochemistry at the sulfur atom did not influence the calculations and the results are presented here for a single diastereoisomer at the sulfur atom.

Starting from 10, the two divergent internal eliminations (Ei) discussed above were envisaged (Fig. 1). Deprotonation of the anomeric position (path a) was found to be easy (TS-a, $\Delta \mathrm{G}^{\#}=$ $21.2 \mathrm{kcal}^{\mathrm{mol}}{ }^{-1}$ ), leading to the D-glucono-? ?-thionolactone 12 and formation of tert-butyl sulfenic acid. In the case of path $b$, which involves one of the nine hydrogen atoms of the tertbutyl groups, and leads to product 14 and isobutene, a higher activation barrier of $\Delta \mathrm{G}^{\#}=24.9 \mathrm{kcal} . \mathrm{mol}^{-1}$ (TS-b) was calculated. This is in agreement with the synthetic work, as the thermal ?-elimination delivered the thionolactone 12 in moderate yield while the benzyl-protected product 14 was not observed.

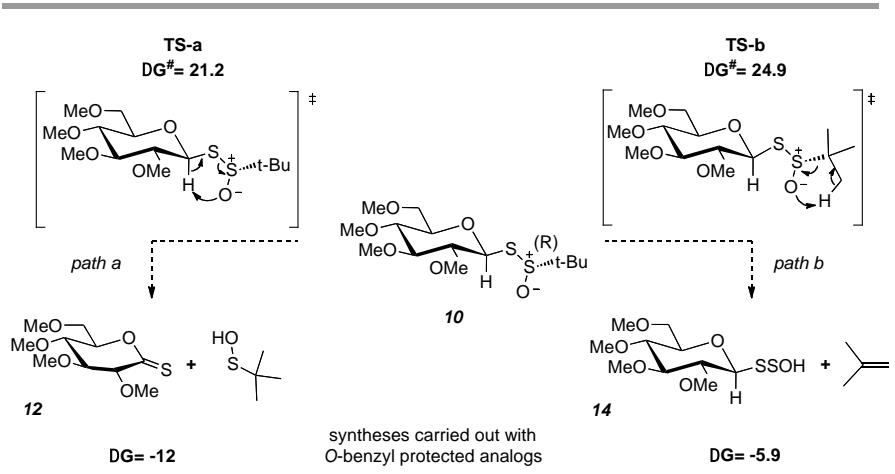

Figure 1. Calculations for Ei eliminations, involving either anomeric or tert-butyl protons (paths $a, b) . \Delta \mathrm{G}$ in kcal.mol ${ }^{-1}$

As a possibility for the puzzling formation of $\mathbf{1 1}$ from 10, path c was envisioned (Fig. 2). For this two-step pathway, a 1,3 shift of the tert-butyl thiosulfinate group led first to $10^{\prime}$ (Ts-c, $\Delta \mathrm{G}^{\#}=$ $36.3 \mathrm{kcal}^{\mathrm{mol}}{ }^{-1}$ ), which subsequently could react through an $\mathrm{Ei}$ elimination (TS-d, $\Delta \mathrm{G}^{\#}=10.9 \mathrm{kcal} . \mathrm{mol}^{-1}$ ) leading to $\mathbf{1 1}$ and tertbutyl thiosulfenic acid. Due to the high activation energy of TSc, this pathway can thus be excluded. 


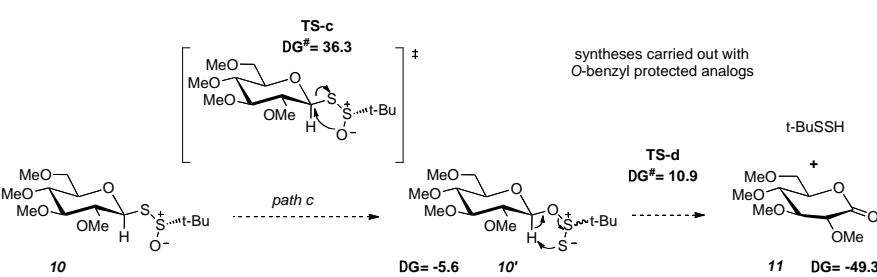

Figure 2. 1,3 Shift of the thiosulfinate group in 10, followed by Ei elimination (path $c$ ). $\Delta \mathrm{G}$ in $\mathrm{kcal}^{\mathrm{mol}}{ }^{-1}$

At this point, since the formation of the experimentally observed D-gluconolactone $\mathbf{1 1}$ cannot be explained through path $c$, we wondered whether lactone $\mathbf{1 1}$ could be formed due to hydrolysis of D-glucono-thionolactone 12. In this event, since the reaction was conducted under anhydrous conditions, water had to be formed as the reaction proceeded. Interestingly, Block et al. ${ }^{67}$ reported the dismutation of tertbutyl sulfenic acid, giving rise to tert-butyl-2-methyl-propane2-sulfinothioate (or thiosulfinate) and water ( 0.5 eq. each, Fig. 3). The computed thermodynamics for the dismutation $(\Delta \mathrm{G}=-$ $4.4 \mathrm{kcal} \mathrm{mol}^{-1}$ ) were in agreement with the experimental observations of Block. ${ }^{67}$ Subsequently, water, assisted by the coordination of the thiosulfinate, can trigger the hydrolysis of compound 12 through TS-e $\left(\Delta \mathrm{G}^{\#}=30.6 \mathrm{kcal} . \mathrm{mol}^{-1}\right)$, providing gluconolactone 11 and hydrogen sulfide ( 0.5 eq. each). This proposed mechanism is in agreement with the experimental formation of lactones 11 and 12 in a 1:1 ratio.

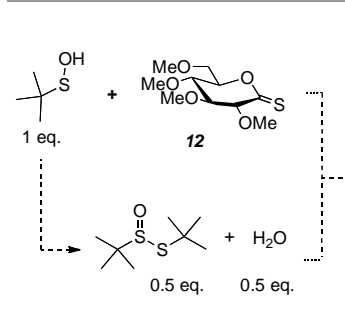

Dismutation G= -4.4

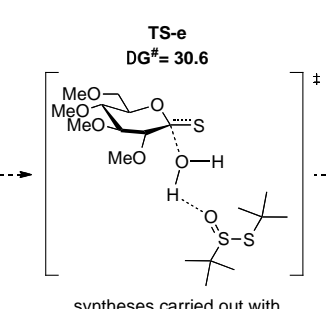
syntheses carried out with
O-benzyl protected analogs

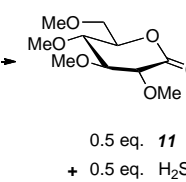

$G=-18.1$
Figure 3. Dismutation of tert-butyl sulfenic acid, followed by hydrolysis of thionolactone 12. $\Delta \mathrm{G}$ in kcal. $\mathrm{mol}^{-1}$

To further confirm that lactone $\mathbf{1 1}$ came from the hydrolysis of thionolactone 12 (Fig. 4), we computed the attack of di-tertbutyl thiosulfinate on substrate 12 (Fig. 4). TS-f $\left(\Delta G^{\#}=41.5\right.$ $\mathrm{kcal} . \mathrm{mol}^{-1}$ ) could lead indeed to the formation of $\mathbf{1 1}$ and tertbutyl-2-methylpropane-2-sulfinodithioate (or dithiosulfinate) without the assistance of a water molecule. Since the $\Delta \Delta \mathrm{G}^{\#}$ between TS-e and TS-f was $10.9 \mathrm{kcal}^{\mathrm{mol}} \mathrm{m}^{-1}$ in favor of the former, water hydrolysis pathway was confirmed to be the most energetically reasonable route.

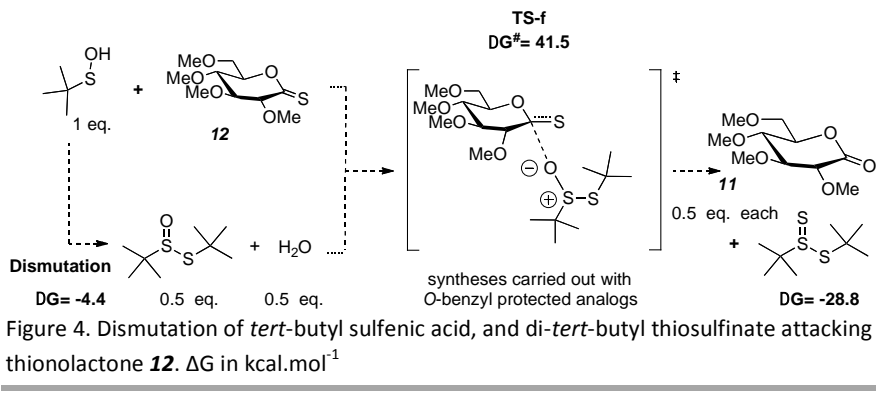

In summary, these calculations showed a good agreement with the synthetic results, as they indicated that the thermal elimination via 5-membered transition states preferentially involved the anomeric proton rather than one of the nine tertbutyl hydrogen atoms, thus yielding the target gluconothionolactone. Simultaneous formation of gluconolactone through a 1,3-shift of the thiosulfinate moiety, followed by $\mathrm{Ei}$ can be ruled out. Based on the reported dismutation of tert-butyl sulfenic acid which yielded di-tertbutyl thiosulfinate and water ( 0.5 eq. each), the calculations predicted that 12 can be hydrolysed into 11 (0.5 eq.). Thus, in order to optimize the yield of the target gluconothionolactone 12, water, formed while the thermal elimination proceeds, has to be trapped by efficient means, for example by adding activated molecular sieves to the reaction medium. ${ }^{46,47}$

\section{Enzyme kinetics}

Previous structure-activity relationship studies ${ }^{15,33,38}$ revealed that phenyl oxathiazole 5 a was a moderate inhibitor of GP $\left(K_{\mathrm{i}}=\right.$ $26 \mu \mathrm{M})$. Other para-substituted phenyl analogues ( $R=$ phenyl, $\mathrm{NO}_{2}, \mathrm{CN}$ ) exhibited lower inhibitory properties with $\mathrm{IC}_{50}$ values in the high micromolar range for $\mathbf{5 b}, \mathbf{c}, \mathbf{g}$. The para-fluoro and para-methoxy analogues $\mathbf{5 d}$ and $\mathbf{5 e}$ had similar and slightly better inhibitory potential than 5a $\left(K_{\mathrm{i}}=28\right.$ and $8 \mu \mathrm{M}$, respectively). As observed for several other classes of glucosebased GP inhibitors, ${ }^{14,15,32,35,68}$ the 2-naphthyl oxathiazole derivative $\mathbf{5 h}$ was the best inhibitor among the series of compounds studied, and one of the best among glucose-based GP inhibitors. Substitution by a para-carboxy group on the phenyl $(\mathbf{5 j})$ resulted in a good inhibitory potency $\left(K_{\mathrm{i}}=238 \mu \mathrm{M}\right)$, while the 2-quinolinyl analogue 5k was more potent $\left(K_{\mathrm{i}}=26\right.$ $\mu \mathrm{M})$, although much less potent than the 2-naphthyl analogue $\mathbf{5 h}$. In spite of the size of the 9-phenanthryl residue, compound 5I displayed moderate inhibitory properties. 
Table 2: Kinetic data measured for spiro-oxathiazoles $\mathbf{5 a - e , g , h , j - I ~ f o r ~ t h e ~ i n h i b i t i o n ~ o f ~}$ $\mathrm{RMGP} b$

\begin{tabular}{|c|c|c|}
\hline Compound & Structure & $\begin{array}{c}\mathrm{IC}_{50} \text { or } K_{\mathrm{i}} \text { values } \\
(\mu \mathrm{M})\end{array}$ \\
\hline $5 a$ & & $K_{\mathrm{i}}=26 \pm 2.1^{38}$ \\
\hline $5 b$ & & $I C_{50}=250^{33}$ \\
\hline 5c & & $1 C_{50}=700^{33}$ \\
\hline $5 d$ & & $K_{\mathrm{i}}=28 \pm 2.8^{38}$ \\
\hline $5 e$ & & $K_{\mathrm{i}}=8 \pm 0.9^{38}$ \\
\hline $5 g$ & & $\mathrm{IC}_{50}=250^{33}$ \\
\hline $5 \mathrm{~h}$ & & $K_{\mathrm{i}}=0.16 \pm 0.04^{33,38}$ \\
\hline $5 j$ & & $K_{\mathrm{i}}=238.5$ \\
\hline $5 k$ & & $K_{\mathrm{i}}=26.02$ \\
\hline 51 & & $\mathrm{IC}_{50}=32.4 \pm 1.1$ \\
\hline
\end{tabular}

\section{In vitro pharmacological evaluations}

Guided by the kinetic results and for an in depth evaluation of his inhibitory property, the glucose-based GP inhibitor $\mathbf{5 h}$ with the best $\mathrm{K}_{\mathrm{i}}$ value was assayed in vitro with rat and human hepatocytes in primary culture (see Table S1). The potent in vitro GP inhibitor 1,4-dideoxy-1,4-imino-D-arabinitol (DAB, $\mathrm{K}_{\mathrm{i}}=$ $400 \mathrm{nM})^{69}$ was selected as the reference compound for its established in vivo activity in a GP-dependent glycaemia study. ${ }^{3,69,70}$ An evaluation of glucose release after glucagon stimulation in primary rat hepatocytes was performed. Further evaluation in human hepatocytes for the candidate $\mathbf{5 h}$ was accomplished by measuring both glucose release and intracellular glycogen for an assessment of species specificity.
$\mathrm{IC}_{50}$ Values calculated for glucose release (product of GPmediated glycogen depolymerisation) or intracellular glycogen content (substrate of GP-mediated glycogen depolymerisation) are similar (2-5 $\mu \mathrm{M}$, Table 3$)$ in human hepatocytes. In the studied cellular model, this result demonstrates that compound $\mathbf{5 h}$ affected glycogenolysis via GP inhibition.

Table 3: In vitro $\mathrm{IC}_{50}$ for compound $\mathbf{5 h}$ based on glucose release and intracellular glycogen content after glucagon stimulation in rat and human primary hepatocytes in primary cultures

\begin{tabular}{|l|l|l|l|}
\hline \multirow{2}{*}{ Compound } & \multicolumn{2}{|l|}{$\begin{array}{l}\text { Glucose release } \\
\text { IC }\end{array}$} & \multirow{2}{*}{$\begin{array}{l}\text { Intracellular glycogen } \\
\text { IC }\end{array}$ ( $(\mu \mathrm{M})^{\mathrm{a}}$} \\
\cline { 2 - 3 } & Rats & Humans & \\
\hline 5h & 6.7 & $2.08 \pm 1.51$ & $4.88 \pm 1.20$ \\
\hline DAB & 8 & $2.17 \pm 1.30$ & $1.10 \pm 1.11$ \\
\hline
\end{tabular}

${ }^{a} \mathrm{IC}_{50}$ values are average of three to five measurements (see supporting information).

${ }^{b} \mathrm{IC}_{50}$ values are average triplicate measurements for three human hepatocyte cultures (see supporting information).

The concentration-response curves obtained for glucose release (Fig. 5) and observed intracellular glycogen content (Fig. 6) provided a basis for a comparison against DAB. Compound $\mathbf{5 h}$ performed slightly better than DAB in terms of concentrations to obtain $50 \%$ inhibition on glucose release in rat and human hepatocytes. Such concentrations are compatible with potential pharmacological applications.

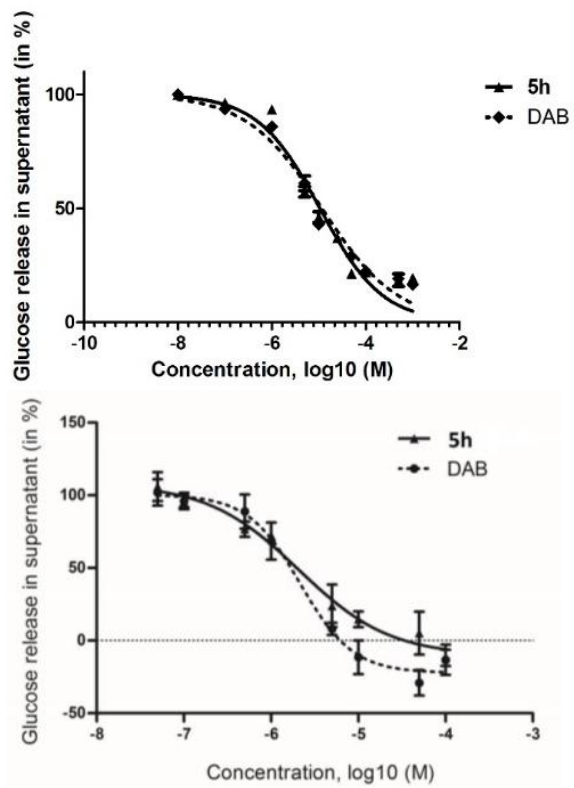

Figure 5: Glucose release from rat and human hepatocytes after glucagon stimulation in vitro measured in the presence of compound $5 \mathrm{~h}$ versus $\mathrm{DAB}$ as the reference compound. Top: Rat hepatocytes, bottom: human hepatocytes 


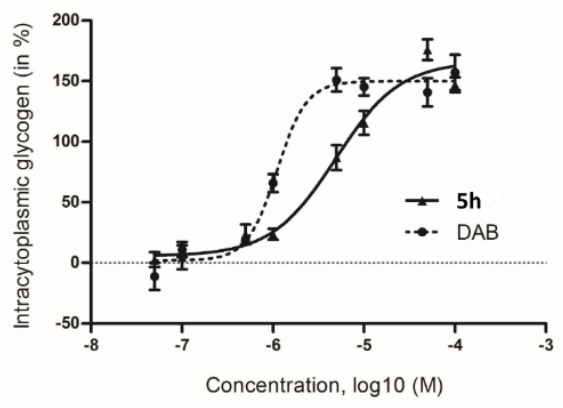

Figure 6: Intracellular glycogen content in human hepatocytes after glucagon stimulation in vitro measured in the presence of compounds $5 \mathrm{~h}$ versus DAB as the reference compound

\section{In vivo pharmacological evaluations}

The glucagon challenge test in the Zucker $f a / f a$ rat model was performed to measure the glucose-lowering effect in vivo with for compound $\mathbf{5 h}$. This animal model, displaying hyperphagia and insulin resistance with hyperinsulinemia, was chosen due to its high hepatic glycogen content. We used glucagon (200 $\mu \mathrm{g} / \mathrm{kg}$, in a single subcutaneous " $\mathrm{SC}$ " administration) as hyperglycemic agent. A dose-dependent effect was clearly observed when compound $\mathbf{5} \boldsymbol{h}$ was introduced orally in a single administration (Figure 7).
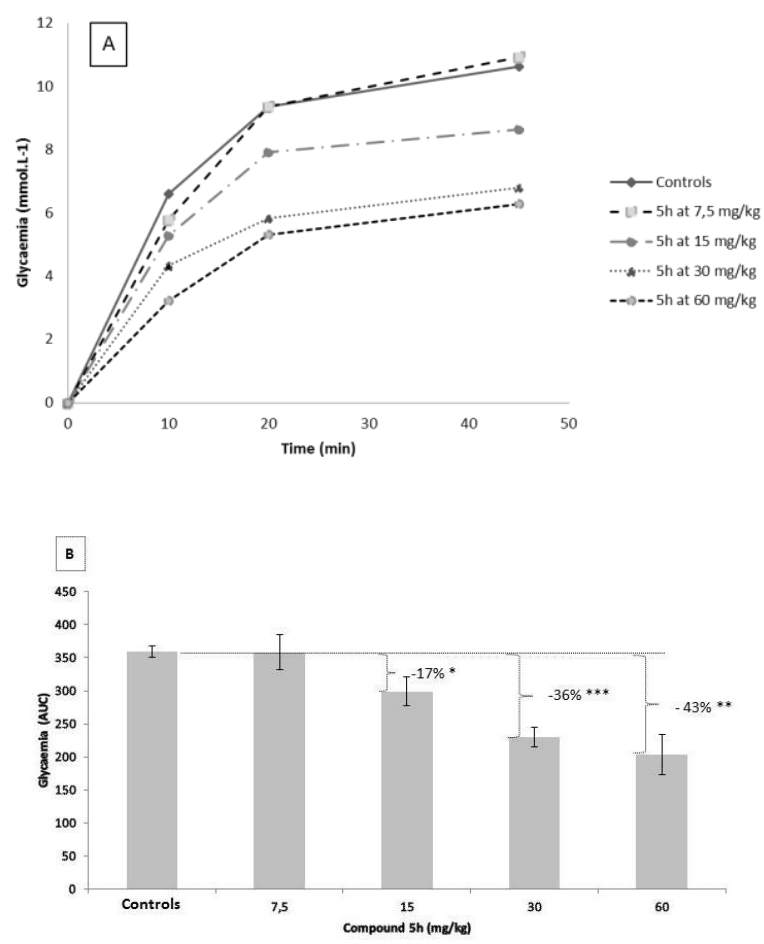

Figure 7. Hepatic glucose production of the unprotected compound $5 \mathrm{~h}$ obtained in Zucker fa/fa rats in acute in vivo glucagon challenge. (A) Kinetics of glucose output for $45 \mathrm{~min}$ after acute glucagon administration in $\mathrm{mmol} / \mathrm{L}$. (B) Area Under the Curves (AUC) corresponding to glucose release for $45 \mathrm{~min}$ after acute glucagon administration. ${ }^{*} \mathrm{p}<0.05$ for $15 \mathrm{mg} / \mathrm{kg},{ }^{* * *} \mathrm{p}<0.001$ for $30 \mathrm{mg} / \mathrm{kg}$ and ${ }^{* *} \mathrm{p}<0.01$ for $60 \mathrm{mg} / \mathrm{kg}$
Liver glucose output kinetics (Fig. 7A) and their areas under the curves (AUC) for $45 \mathrm{~min}$ (Fig. 7B) pointed to a dosedependent decrease in liver glucose production ranging from 7.5 to $60 \mathrm{mg} / \mathrm{kg}$ (Fig. 7B). The rate of endogenous glucose production being elevated in type 2 diabetes renders this effect on liver output relevant for therapeutic applications. ${ }^{71}$ Compound $\mathbf{5 h}$ was then selected for a subchronic oral administration with a dose corresponding to the first significantly effective in the acute in vivo glucagon challenge test $(30 \mathrm{mg} / \mathrm{kg}$ ). In a glucagon challenge test performed after 4 days of treatment, a nearly $33 \%$ reduction of hepatic glucose production $(p<0.05)$ was observed (Fig. $8 A-B)$. It is worth pointing out that the activity of glycogen phosphorylase was preserved, in spite of the subchronic treatment, since hepatic glucose production was not further reduced.
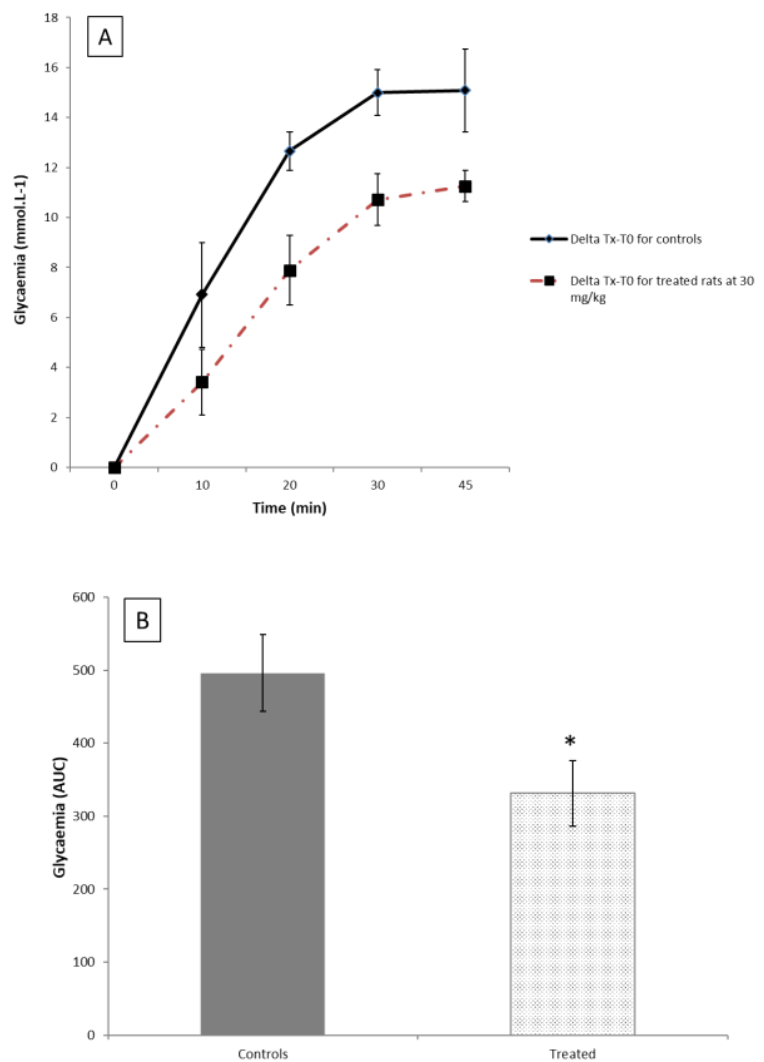

Figure 8. Plasma glucose concentration of the unprotected compound $\mathbf{5 h}$ obtained in Zucker $f a / f a$ rats subjected to in vivo glucagon challenge after subchronic administrations. (A) Kinetics of glucose output for $45 \mathrm{~min}$ after acute glucagon administration in $\mathrm{mmol} / \mathrm{L}$. (B) Area Under the Curve (AUC) corresponding to glucose release for $\mathbf{4 5} \mathrm{min}$ after acute glucagon administration. Plasma glucose concentrations were expressed as variations (delta), meaning that the basal value of glycaemia was substracted for each individual value and for each rat.

As a summary, the in vitro and in vivo pharmacological effects of glucose-based spiro-oxathiazole $\mathbf{5 h}$ were analyzed and they validated its potent GP inhibition both in vitro, in cell assays and in a diabetic rat model (in vivo). In rat and human hepatocytes, compound $\mathbf{5 h}$ reduced glucagon-stimulated glucose output through glycogenolysis inhibition (Table 3, Fig. 
5). No species specificity could be observed since the potency of compound $\mathbf{5 h}$ for inhibition of glucose output were comparable between rat and human cells (Table 3 ) as previously reported. ${ }^{72,73}$ Compound $\mathbf{5 h}$ was efficient in vivo in the Zucker $f a / f a$ rat model of insulin resistance and a dosedependent decrease of hepatic glucose output to a maximal $43 \%$ was observed (Fig. 7). This glucose lowering effect allows for the design of therapeutic applications due to a high rate of endogenous glucose production in type 2 diabetes. ${ }^{71}$ Indeed, hepatic glucose production tends to match the values usually obtained in Wistar normal rat.

The complete suppression of glucagon-induced glucose output in the presence of DAB appears in sharp contrast with the moderate level of inhibition of GP. ${ }^{70}$ The incomplete inhibition of GP by compound $\mathbf{5 h}$ is advantageous for limiting potential side effects. In addition, the absence tissue-specificity between liver and muscle GP isoforms could impair exercise-mediated metabolism of muscle glycogen. Preserving a minimum level of activity will limit this risk, although the selection of a liverspecific inhibitor preferred for long-term therapy remains a valuable research challenge. ${ }^{74}$ Even though hypoglycaemia could be a detrimental consequence of GP inhibition, hepatic glucose production was not further reduced after repeated administrations of compound $\mathbf{5} \mathbf{h}$, indicating a residual activity of GP thus limiting the risk of hypoglycaemia (Fig. 7).

\section{Conclusion}

Type 2 diabetes is a major public health problem and design of glycogen phosphorylase inhibitors targeting the catalytic site of the enzyme appears as a promising strategy for a better control of hyperglycaemia. An especially potent group of GP inhibitors is represented by some glucopyranosylidene-spiroheterocycles, among them spiro-oxathiazoles. A new synthesis has now been elaborated for this valuable class of compounds by the 1,3-dipolar cycloaddition of an aryl nitrile oxide to a glucono-thionolactone affording in one step the spirooxathiazole moiety. The thionolactone was obtained from the thermal rearrangement of a thiosulfinate precursor according to Fairbanks' protocols, although with a revisited outcome and also based on DFT calculations. The 2-naphthyl substituted glucose-based spiro-oxathiazole $\mathbf{5 h}$ has recently been identified as one of the most potent GP inhibitors with a $K_{i}$ of $160 \mathrm{nM}$ against RMGPb. Further evaluation in vitro using rat and human hepatocytes demonstrated that compound $\mathbf{5 h}$ was promising as a potential anti-hyperglycaemic druggable compound as it performed better than DAB used as a positive control. Investigation in Zucker $f a / f a$ rat model in acute and subchronic assays further confirmed the potency of compound 5h since it lowered blood glucose levels by $\sim 36 \%$ at $30 \mathrm{mg} / \mathrm{kg}$ and $\sim 43 \%$ at $60 \mathrm{mg} / \mathrm{kg}$. This indicates that compound $5 \mathrm{~h}$ can be considered as a powerful anti-hyperglycemic agent in the context of type 2 diabetes. The present study is one of the few in vivo investigations for glucose-based GP inhibitors and provides data in animal models for such drug candidates. This study is also an example of molecular diversity-oriented strategies to identify the fittest inhibitor of GP and from the identification of this candidate, multigram-scale preparations for in vivo validation called for a robust and faster synthetic route to the target glucose-based spiro-oxathiazole.

\section{Conflicts of interest}

There are no conflicts to declare

\section{Acknowledgements}

Financial support from CNRS and the Hungarian Academy of Sciences, University Claude Bernard Lyon 1, the French Agence Nationale de la Recherche (ANR-08-BLAN-0305) as well as the Hungarian National Research, Development and Innovation Office (OTKA K109450), and the EU co-financed by the European Regional Development Fund under the project GINOP-2.3.2-15-2016-00008 are gratefully acknowledged. We are grateful to Prof. A.J. Fairbanks for providing the internal report of B. Wilkinson (January 2008) on the research carried out under his supervision. CCIR-ICBMS (UCBL) is gratefully acknowledged for the allocation of computational resources.

\section{Notes and references}

1. Z. H. Israili, Am. J. Ther., 2011, 18, 117-152.

2. N. Kerru, A. Singh-Pillay, P. Awolade and P. Singh, Eur. J. Med. Chem., 2018, 152, 436-488.

3. B. Andersen, A. Rassov, N. Westergaard and K. Lundgren, Biochem. J., 1999, 342, 545-550.

4. R. Kurukulasuriya, J. T. Link, D. J. Madar, Z. Pei, J. J. Rohde, S. J. Richards, A. J. Souers and B. G. Szczepankiewicz, Curr. Med. Chem., 2003, 10, 99-121.

5. B. R. Henke, Inhibition of glycogen phosphorylase as a strategy for the treatment of type 2 diabetes mellitus in New Therapeutic Strategies for Type 2 Diabetes: Small Molecule Approaches, ed. R. M. Jones, RSC Drug Discovery, Dorset Press, Dorchester, UK, 2012, Chap. 12, pp. 324-365.

6. J. Hayes, A. Kantsadi and D. Leonidas, Phytochem. Rev., 2014, 13, 471-498.

7. L. Somsák, K. Czifrák, M. Tóth, E. Bokor, E. D. Chrysina, K. M. Alexacou, J. M. Hayes, C. Tiraidis, E. Lazoura, D. D. Leonidas, S. E. Zographos and N. G. Oikonomakos, Curr. Med. Chem., 2008, 15, 2933-2983.

8. M. Donnier-Maréchal and S. Vidal, Exp. Opin. Ther. Pat., 2016, 26, 199-212.

9. J. M. Fernández-Novell and M. Díaz-Lobo, Appl. Biochem. Biotechnol., 2018, 184, 909-918.

10. T. Fischer, S. M. Koulas, A. S. Tsagkarakou, E. Kyriakis, G. A. Stravodimos, V. T. Skamnaki, P. G. V. Liggri, S. E. Zographos, R. Riedl and D. D. Leonidas, Molecules, 2019, 24, 1322.

11. V. Maffeis, K. Mavreas, F. Monti, M. Mamais, T. Gustavsson, E. D. Chrysina, D. Markovitsi, T. Gimisis and A. Venturini, Phys. Chem. Chem. Phys., 2019, 21, 7685-7696.

12. M. Díaz-Lobo, A. L. Concia, L. Gómez, P. Clapés, I. Fita, J. J. Guinovart and J. C. Ferrer, Org. Biomol. Chem., 2016, 14, 91059113.

13. E. D. Chrysina, Mini-Rev. Med. Chem., 2010, 10, 1093-1101.

14. L. Somsák, C. R. Chimie, 2011, 14, 211-223. 
15. J.-P. Praly and S. Vidal, Mini-Rev. Med. Chem., 2010, 10, 11021126.

16. K. Szabó, S. Kun, A. Mándi, T. Kurtán and L. Somsák, Molecules, 2017, 22, 1760.

17. K. E. Szabó, E. Kyriakis, A.-M. G. Psarra, A. G. Karra, Á. Sipos, T. Docsa, G. A. Stravodimos, E. Katsidou, V. T. Skamnaki, P. G. V. Liggri, S. E. Zographos, A. Mándi, S. B. Király, T. Kurtán, D. D. Leonidas and L. Somsák, J. Med. Chem., 2019, 62, 6116-6136.

18. É. Bokor, S. Kun, D. Goyard, M. Tóth, J.-P. Praly, S. Vidal and L. Somsák, Chem. Rev., 2017, 117, 1687-1764.

19. S. Kun, J. Begum, E. Kyriakis, E. C. V. Stamati, T. A. Barkas, E. Szennyes, É. Bokor, K. E. Szabó, G. A. Stravodimos, Á. Sipos, T. Docsa, P. Gergely, C. Moffatt, M. S. Patraskaki, M. C. Kokolaki, A. Gkerdi, V. T. Skamnaki, D. D. Leonidas, L. Somsák and J. M. Hayes, Eur. J. Med. Chem., 2018, 147, 266-278.

20. S. Kun, É. Bokor, Á. Sipos, T. Docsa and L. Somsák, Molecules, 2018, 23, 666.

21. E. Kyriakis, T. G. A. Solovou, S. Kun, K. Czifrák, B. Szőcs, L. Juhász, É. Bokor, G. A. Stravodimos, A. L. Kantsadi, D. S. M. Chatzileontiadou, V. T. Skamnaki, L. Somsák and D. D. Leonidas, Bioorg. Chem., 2018, 77, 485-493.

22. L. Somsák, É. Bokor, L. Juhász, S. Kun, L. Lázár, É. Juhász-Tóth and M. Tóth, Pure Appl. Chem., 2019, 91, 1159-1175.

23. D. Barr, E. Szennyes, É. Bokor, Z. H. Al-Oanzi, C. Moffatt, S. Kun, T. Docsa, Á. Sipos, M. P. Davies, R. Mathomes, T. J. Snape, L. Agius, L. Somsák and J. M. Hayes, ACS Chem. Biol., 2019, 14, 1460-1470.

24. E. Szennyes, É. Bokor, T. Docsa, Á. Sipos and L. Somsák, Carbohydr. Res., 2019, 472, 33-41.

25. E. Szennyes, É. Bokor, P. Langer, G. Gyémánt, T. Docsa, Á. Sipos and L. Somsák, New J. Chem., 2018, 42, 17439-17446.

26. É. Bokor, E. Kyriakis, T. G. A. Solovou, C. Koppány, A. L. Kantsadi, K. E. Szabó, A. Szakács, G. A. Stravodimos, T. Docsa, V. T. Skamnaki, S. E. Zographos, P. Gergely, D. D. Leonidas and L. Somsák, J. Med. Chem., 2017, 60, 9251-9262.

27. T. Docsa, K. Czifrák, C. Hüse, L. Somsák and P. Gergely, Mol. Med. Rep., 2011, 3, 477-481.

28. T. Docsa, B. Marics, J. Nemeth, C. Huse, L. Somsak, P. Gergely and B. Peitl, Top. Curr. Med. Chem., 2015, 15, 2390-2394.

29. L. Nagy, T. Docsa, M. Szántó, A. Brunyánszki, C. Hegedűs, J. Márton, B. Kónya, L. Virág, L. Somsák, P. Gergely and P. Bai, PLOS ONE, 2013, 8, e69420.

30. L. Nagy, J. Márton, A. Vida, G. Kis, É. Bokor, S. Kun, M. Gönczi, T. Docsa, A. Tóth, M. Antal, P. Gergely, B. Csóka, P. Pacher, L. Somsák and P. Bai, Br. J. Pharmacol., 2018, 175, 301-319.

31. M. Benltifa, J. M. Hayes, S. Vidal, D. Gueyrard, P. G. Goekjian, J.P. Praly, G. Kizilis, C. Tiraidis, K.-M. Alexacou, E. D. Chrysina, S. E. Zographos, D. D. Leonidas, G. Archontis and N. G. Oikonomakos, Bioorg. Med. Chem., 2009, 17, 7368-7380.

32. M. Benltifa, S. Vidal, D. Gueyrard, P. G. Goekjian, M. Msaddek and J.-P. Praly, Tetrahedron Lett., 2006, 47, 6143-6147.

33. V. Nagy, M. Benltifa, S. Vidal, E. Berzsényi, C. Teilhet, K. Czifrák, G. Batta, T. Docsa, P. Gergely, L. Somsák and J.-P. Praly, Bioorg. Med. Chem., 2009, 17, 5696-5707.

34. L. Somsák, É. Bokor, B. Czibere, K. Czifrák, C. Koppány, L. Kulcsár, S. Kun, E. Szilágyi, M. Tóth, T. Docsa and P. Gergely, Carbohydr. Res., 2014, 399, 38-48.

35. D. Goyard, B. Kónya, A. S. Chajistamatiou, E. D. Chrysina, J. Leroy, S. Balzarin, M. Tournier, D. Tousch, P. Petit, C. Duret, P. Maurel, L. Somsák, T. Docsa, P. Gergely, J.-P. Praly, J. AzayMilhau and S. Vidal, Eur. J. Med. Chem., 2016, 108, 444-454.
36. J.-P. Praly, R. Faure, B. Joseph, L. Kiss and P. Rollin, Tetrahedron, 1994, 50, 6559-6568.

37. L. Brochard, B. Joseph, M.-C. Viaud and P. Rollin, Synth. Commun., 1994, 24, 1403-1414.

38. L. Somsák, V. Nagy, S. Vidal, K. Czifrák, E. Berzsényi and J.-P. Praly, Bioorg. Med. Chem. Lett., 2008, 18, 5680-5683.

39. S. E. Cobb, K. F. Morgan and N. P. Botting, Tetrahedron Lett., 2011, 52, 1605-1607.

40. C. Taillefumier and Y. Chapleur, Chem. Rev., 2004, 104, 263-292.

41. G. Enderlin, C. Taillefumier, C. Didierjean and Y. Chapleur, Tetrahedron: Asymm., 2005, 16, 2459-2474.

42. X. Li, R. Wang, Y. Wang, H. Chen, Z. Li, C. Ba and J. Zhang, Tetrahedron, 2008, 64, 9911-9920.

43. M. Hürzeler, B. Bernet and A. Vasella, Helv. Chim. Acta, 1993, 76, 995-1012.

44. D. Kahne, D. Yang, J. J. Lim, R. Miller and E. Paguaga, J. Am. Chem. Soc., 1988, 110, 8716-8717.

45. T. Belhadj and P. G. Goekjian, Tetrahedron Lett., 2005, 46, 81178120.

46. K. Chayajarus and A. J. Fairbanks, Tetrahedron Lett., 2006, 47, 3517-3520.

47. B. L. Wilkinson and A. J. Fairbanks, Tetrahedron Lett., 2008, 49, 4941-4943.

48. M. Hürzeler, B. Bernet, T. Mäder and A. Vasella, Helv. Chim. Acta, 1993, 76, 1779-1801.

49. B. Bernet, T. Mäder and A. Vasella, Helv. Chim. Acta, 1997, 80, 1260-1279.

50. W. Szeja and J. Bogusiak, Carbohydr. Res., 1987, 170, 235-239.

51. M. Hürzeler, B. Bernet and A. Vasella, Helv. Chim. Acta, 1992, 75, 557-588.

52. A. Pastore, S. Valerio, M. Adinolfi and A. Iadonisi, Chem. Eur. J., 2011, 17, 5881-5889.

53. J. G. Riley and T. B. Grindley, J. Carbohydr. Chem., 2001, 20, 159169.

54. M. Niemietz, L. Perkams, J. Hoffman, S. Eller and C. Unverzagt, Chem. Commun., 2011, 47, 10485-10487.

55. A. Dondoni and A. Marra, J. Org. Chem., 2006, 71, 7546-7557.

56. E. Block, J. Am. Chem. Soc., 1972, 94, 644-645.

57. H. P. Reisenauer, G. Mloston, J. Romanski and P. R. Schreiner, Eur. J. Org. Chem., 2012, 3408-3415.

58. B. Mondal, D. Mandal and A. K. Das, J. Phys. Chem. A, 2011, 115, 3068-3078.

59. W. M. Doane, B. S. Shasha, C. R. Russell and C. E. Rist, J. Org. Chem., 1965, 30, 3071-3075.

60. O. Jackowski, F. Chrétien, C. Didierjean and Y. Chapleur, Carbohydr. Res., 2012, 356, 93-103 and references therein.

61. J.-R. Pougny, J. Carbohydr. Chem., 1986, 5, 529-535.

62. A. Schönberg and L. v. Vargha, Chem. Ber., 1930, 63, 178-180.

63. G. C. Lloyd-Jones, J. D. Moseley and J. S. Renny, Synthesis, 2008, 661-689.

64. R. Steudel, Y. Drozdova, R. H. Hertwig and W. Koch, J. Phys. Chem., 1995, 99, 5319-5324.

65. M. Mikolajczyk, M. Cypryk and G. Krasiński, J. Mol. Struct. THEOCHEM, 2008, 863, 105-110.

66. K. B. Wiberg and Y. Wang, Arkivoc, 2011, v, 45-56.

67. E. Block, Angew. Chem. Int. Ed., 1992, 31, 1135-1178.

68. M. Tóth, S. Kun, É. Bokor, M. Benltifa, G. Tallec, S. Vidal, T. Docsa, P. Gergely, L. Somsák and J.-P. Praly, Bioorg. Med. Chem., 2009, 17, 4773-4785.

69. K. Fosgerau, N. Westergaard, B. Quistorff, N. Grunnet, M. Kristiansen and K. Lundgren, Arch. Biochem. Biophys., 2000, 380, 274-284. 
70. P. Mackay, L. Ynddal, J. V. Andersen and J. G. McCormack, Diabetes Obes. Metab., 2003, 5, 397-407.

71. M. Roden and E. Bernroider, Best Pract. Res. Clin. Endocrinol. Metab., 2003, 17, 365-383.

72. S. Freeman, J. B. Bartlett, G. Convey, I. Hardern, J. L. Teague, S. J. G. Loxham, J. M. Allen, S. M. Poucher and A. D. Charles, Br. J. Pharmacol., 2006, 149, 775-785.

73. W. H. Martin, D. J. Hoover, S. J. Armento, I. A. Stock, R. K. McPherson, D. E. Danley, R. W. Stevenson, E. J. Barrett and J. L. Treadway, Proc. Natl. Acad. Sci. U.S.A., 1998, 95, 1776-1781.

74. M. Combettes and C. Kargar, Thérapie, 2007, 62, 293-310. 